\title{
ANALISIS FAKTOR PRODUKSI DAN KEBUTUHAN TENAGA KERJA \\ (LUAR KELUARGA) PADA USAHATANI PADI SAWAH DI KABUPATEN LEBONG PROVINSI BENGKULU
}

\author{
THE ANALYSIS OF PRODUCTION FACTORS AND LABOR NEEDS \\ (OUTSIDE OF HOUSEHOLD) ON PADDY FARMING \\ AT LEBONG DISTRICT BENGKULU PROVINCE
}

\author{
Evi Andriani \\ Program Studi Agribisnis, Fakultas Pertanian, Universitas Dehasen Bengkulu \\ Email : andrianievi20@yahoo.co.id
}

\begin{abstract}
ABSTRAK
Penelitian ini bertujuan : (1) mengetahui jumlah permintaan tenaga kerja (luar keluarga) dan (2) mengetahui factor-faktor produksi yang mempengaruhi kebutuhan permintaan tenaga kerja pada usahatani padi sawah. Penelitian ini dilaksanakan dari bulan maret sampai bulan juni tahun 2015. Teknik penentuan sampel pada penelitian adalah secara acak sederhana (simple random sampling). Jumlah sampel sebanyak 30 petani pemilik sekaligus penggarap sawah. Jenis data yang digunakan dalam penelitian ini adalah data primer dan data sekunder yang akan dianalisis secara kualitatif maupun kuantitatif. Hasil penelitian menunjukkan bahwa (1). Permintaan tenaga kerja pada usahatani padi sawah adalah 22,18 HKSP/Mt untuk tenaga kerja dalam keluarga dan 99,34 HKSP/Mt untuk tenaga kerja luar keluarga, dan (2). Faktor produksi luas lahan, upah tenaga kerja dan penggunaan traktor berpengaruh terhadap permintaan tenaga kerja (luar keluarga) sedangkan faktor produksi harga harga gabah, harga benih, harga pupuk dan harga pestisida tidak berpengaruh terhadap permintaan tenaga kerja luar keluarga pada usahatani padi sawah.
\end{abstract}

Kata Kunci : Permintaan tenaga kerja, luar keluarga, usahatani padi

\begin{abstract}
This research purpose to know number of labor demand in demand of labor derived outside of household in paddy farming and find out the characteristics and factors which are influencing labour demand in paddy farming in Lebong District. The research was uses simple random sampling technique. The number of sampel are 30 farmer. The result of the research showed (1) that farmer 22,18 Day work Equvalent Mean/ farm for the labor of inside household, 1s 99,34 DWEM/farm for labor of outside household, and (2).The significant variabel in faktor of derived outside household that farm is field, wage, untilizing tractor in paddy farming. while price of fertilizer, price of pestised,price of product, is not significant to demand of labour derived in paddy farming.
\end{abstract}

Key word: demand of labour derived outside of household, paddy farming 


\section{PENDAHULUAN}

Ilmu usahatani digunakan untuk mengalokasikan sumberdaya secara efektif dan efisien untuk memperoleh keuntungan yang tinggi (Boediono, 1997; Soekartawi,1995). Jenis usahatani yang dominan di Kabupaten Lebong adalah padi sawah dengan luas sawah 9.329 ha dan produksi padi rata-rata sebesar 39.181,8 ton per/tahun (BPS Lebong, 2014). Dengan adanya kondisi masyarakat yang mayoritas sebagai petani, maka masalah ketenaga kerjaan sangat memegang peranan (Antoni, 2004). Banyaknya yang bekerja disektor pertanian menyebabkan terjadinya permintaan tenaga kerja dari luar keluarga. Penyebab terjadinya penggunaan tenaga kerja luar keluarga pada usaha tani padi sawah dikarenakan ketersediaan tenaga kerja dalam keluarga inti petani yang terbatas menurut luas lahan usahatani yang digarap dan keterbatasan waktu dan tenaga (Haryanto, 1997; Hermanto, 1989).

Dalam usaha pertanian, faktor-faktor produksi (input) seperti bibit, modal, lahan dan tenaga kerja merupakan faktor produksi penting dalam melakukan kegiatan usaha pertanian. Penggunaan input (faktor produksi) yang tepat bertujuan untuk mencapai hasil yang maksimal. Dalam kegiatan usaha pertanian, penggunaan/permintaan tenaga kerja yang baik dan intensif akan sangat menentukan dalam pencapaian hasil (Simanjuntak,1998; Atman, 2007).

Tujuan dari penelitian ini adalah (1) mengetahui besarnya permintaan tenaga kerja (luar keluarga) dan (2) mengetahui faktor-faktor produksi yang mempengaruhi permintaan tenaga kerja luar keluarga pada usahatani padi sawah di Kecamatan Lebong Tengah Kabupaten Lebong.

\section{METODE PENELITIAN}

Penelitian ini dilaksanakan dari bulan Maret sampai Juni tahun 2015. Data yang digunakan berupa data primer dan data sekunder. Data primer diperoleh dari hasil wawancara dan kuisioner, sedangkan data sekunder diperoleh dari literatur-literatur dan instansi-instansi yang terkait (Singarimbun dan Effendi, 1989). Pengambilan sampel dilakukan dengan metode pengambilan acak sederhana (simple random sampling) (Nazir, 2003). Populasi penelitian ini adalah petani pemilik sekaligus penggarap sawah sejumlah 30 responden

\section{Analisis Jumlah Permintaan Tenaga Kerja}

\section{a.Uji Asumsi Klasik Multikolinieritas}

Uji multikolinearitas bertujuan untuk menguji apakah dalam model regresi ditemukan adanya korelasi antar variabel 
bebas (independen). Uji Multikolinearitas dilakukan dengan melihat nilai tolerance dan variance inflation factor (VIF) dari hasil analisis dengan menggunakan SPSS. Apabila nilai tolerance value lebih tinggi daripada 0,10 atau VIF lebih kecil daripada 10 maka dapat disimpulkan tidak terjadi multikolinearitas.

\section{b. Uji Asumsi}

Klasik

\section{Heteroskedasitisitas}

Heteroskedastisitas adalah ketidaksamaan varians dari residual pengamatan kepengamatan lain. Pengujian dilakukan dengan mengamati sebaran pada titik-titik pada scatterplot regresi, dengan ketentuan bahwa titik-titik yang tersebar pada scatterplot regresi tidak membentuk pola tertentu atau tersebar secara acak baik di atas maupun di bawah angka 0 pada sumbu Y.

\section{c.Uji Asumsi Klasik Autokorelasi}

Uji Autokorelasi bertujuan menguji apakah dalam suatu model regresi linear ada korelasi antara kesalahan pengganggu pada periode $\mathrm{t}$ dengan kesalahan pada periode t-1 (sebelumnya). Jika terjadi korelasi maka dinamakan ada problem autokorelasi. Uji autokorelasi dilakukan dengan menggunakan uji Durbin-Watson $(\mathrm{D}-\mathrm{W})$, dengan tingkat $=5 \%$. Apabila DW terletak antara -2 sampai +2 maka tidak $\alpha$ kepercayaan ada autokorelasi.

\section{Analisis Permintaan Kebutuhan Tenaga Kerja (Luar Keluarga)}

Untuk mengetahui besarnya variabelvariabel yang mempengaruhi permintaan tenaga kerja maka menggunakan fungsi produksi Cobb Douglass (Semaoen,1992). Bentuk linear berganda yang digunakan adalah:

$Y=a+b_{1} X_{1}+b_{2} X_{2}+b_{3} X_{3}+b_{4} X_{4}+b_{5}$ $\mathrm{X}_{5}+\mathrm{b}_{6} \mathrm{X}_{6}+\mathrm{b}_{7} \mathrm{D}+\mathrm{u}$.

Keterangan : $\mathrm{Y}=$ Permintaan tenaga kerja dari luar keluarga (HKSP/MT), $\mathrm{X}_{1}=$ Luas lahan $(\mathrm{Ha}), \mathrm{X}_{2}=$ Harga produk $(\mathrm{Rp} / \mathrm{Kg})$, $\mathrm{X}_{3}=$ Harga pupuk $(\mathrm{Rp} / \mathrm{Kg}), \mathrm{X}_{4}=$ Harga pestisida $(\mathrm{Rp} / \mathrm{Lt}), \mathrm{X}_{5}=$ Harga benih $(\mathrm{Rp} / \mathrm{Kg}), \mathrm{X}_{6}=$ Upah tenaga kerja $(\mathrm{Rp} / \mathrm{HKSP}), \mathrm{a}=$ Konstanta, $\mathrm{b}_{\mathrm{i}}=$ Koefisien regresi (besaran yang akan diduga), $\mathrm{D}=$ Dummy Variabel (cara pengolahan lahan), $\mathrm{D}=1$ jika menggunakan hand tractor dan/ atau hewan. 0 jika menggunakan tenaga kerja manusia laki-laki dan/ atau wanita, $\mathrm{U}=$ Kesalahan pengganggu.

Selanjutnya dianalisis menggunakan metode kuadrat terkecil (SPSS) untuk mendapatkan hasil estimasi dengan tingkat kesalahan yang paling kecil. Untuk menguji apakah variabel-variabel bebas secara bersama-sama berpengaruh terhadap variabel terikat digunakan uji bersama atau uji $\mathrm{F}$ dengan hipotesis : Ho : $\mathrm{b} 1=\mathrm{b} 2=\mathrm{b} 3=\mathrm{b} 4=\mathrm{b} 5=\mathrm{b} 6=0$, Hi : ada salah satu bi $\neq 0$, sedangkan untuk menguji pengaruh masing-masing variabel 
bebas terhadap variabel terikat digunakan uji t dengan hipotesis sebagai berikut : Ho : bi $=0, \mathrm{Ha}:$ bi $\neq 0$

\section{HASIL DAN PEMBAHASAN}

Desa Talang Sakti adalah salah satu wilayah yang berada di Kecamatan Lebong Tengah Kabupaten Lebong dengan luas $426 \mathrm{Ha}$, topografinya terletak pada ketinggian 100-500 m dpl, rata-rata temperature $28-32^{\circ} \mathrm{C}$, rata-rata curah hujan antara 2350-3000 mm/tahun dan jumlah hari hujan 135-155 hari (Profil Desa Talang Sakti, 2014).

\section{Karakteristik Petani Padi}

Menurut Mubyarto (1989), umur 15 tahun sampai 50 tahun merupakan umur produktif. Hasil penelitian terhadap 30 petani padi sawah di Talang Sakti menunjukkan umur petani dalam kategori sedang (Tabel 1). Dengan demikian, petani berada pada usia produktif.

Tabel 1. Karakteristik Petani Padi

\begin{tabular}{|c|c|c|c|}
\hline No & Karakteristik & Jenis & Persentase $(\%)$ \\
\hline & & Tua $>(46,67)$ & 30 \\
\hline \multirow[t]{3}{*}{1} & Umur (Tahun) & Sedang $(35,66-46,67)$ & 46,67 \\
\hline & & Muda $<(35,66)$ & 23,33 \\
\hline & & Luas $>(0,5)$ & 66,67 \\
\hline \multirow[t]{3}{*}{2} & Luas Lahan Garapan (Hektar) & Sedang $(0,25-0,5)$ & 33,33 \\
\hline & & Sempit < $(0,25)$ & 0 \\
\hline & & Tinggi (> 13) & 6,67 \\
\hline \multirow[t]{3}{*}{3} & Pendidikan & Sedang $(8-13)$ & 40,00 \\
\hline & & Rendah $(<8)$ & 53,33 \\
\hline & & Banyak (>6) & 3,33 \\
\hline \multirow[t]{3}{*}{4} & Jumlah Anggota Keluarga (Orang) & Sedang $(4-6)$ & 83,34 \\
\hline & & Sedikit $(<4)$ & 13,33 \\
\hline & & Lama (> 30,33) & 20,00 \\
\hline \multirow[t]{2}{*}{5} & Pengalaman Berusahatani (Tahun) & Sedang $(17,67-30,33)$ & 43,33 \\
\hline & & Rendah $(<17,67)$ & 36,67 \\
\hline
\end{tabular}

Sumber : Data Primer Diolah (2015) 
Petani yang memiliki luas lahan dengan katagori luas sebanyak $66,67 \%$ petani dan luas lahan dengan katagori sedang sebanyak 33,33\% (Tabel 1). Dengan demikian luas lahan dimiliki petani mayoritas termasuk katagori luas, sehingga membutuhkan tambahan tenaga kerja luar keluarga.

Tingkat pendidikan petani di daerah penelitian berkisar antara 4-18 tahun, dengan rata-rata 8,27 tahun. Persentase terbesar pendidikan petani adalah sebesar $53,33 \%$ petani mempunyai pendidikan rendah (Tabel 1). Oleh karena itu, banyak yang mengikuti pendidikan non formal, berupa penyuluhan pertanian, latihan maupun pertemuan pertanian lainnya, yang dibimbing oleh petugas penyuluhan lapangan sehingga wawasan petani mengenai usahatani akan menjadi meningkat (Jajat dan Tri, 2010).

Persentase terbesar jumlah keluarga produktif adalah sebesar $83,34 \%$, artinya $83,34 \%$ petani mempunyai jumlah anggota anggota keluarga produktif $4-6$ orang (Tabel 1). Semakin banyak anggota keluarga petani yang dapat dijadikan tenaga kerja untuk membantu pelaksanaan usahatani padi sawah maka akan mengurangi biaya yang dikeluarkan petani dalam hal upah tenaga kerja (Ade et al., 2013).
Hasil penelitian menunjukkan bahwa petani sudah cukup lama berusahatani padi. Persentase terbesar pengalaman usahatani adalah sebesar 43,33\% artinya 43,33\% petani padi sawah di daerah penelitian memiliki pengalaman usahatani selama 17,67 sampai 30,33 tahun (Tabel 1), sehingga diharapkan semakin tingginya kemampuan petani dalam menyikapi kegiatan berkaitan dengan usahataninya.

Petani responden bermata pencaharian pokok sebagai petani sebanyak $100 \%$ yaitu sebanyak 30 orang petani responden (Tabel 2). Sedangkan petani responden yang mempunyai mata pencaharian sampingan yaitu sebanyak 7 orang, dengan persentase terbesar pekerjaan sampingannya tukang sebesar 57,14\% artinya petani memiliki pekerjaan sampingan tukang 4 orang (Tabel 2). Dengan demikian penduduk di daerah penelitian paling banyak yang bermata pencaharian petani. Hal ini menunjukan bahwa semakin banyak yang bermata pencaharian petani, didukung oleh keadaan alamnya untuk pengembangan pertanian terutama untuk pengembangan komoditas padi (Saeful et al.,2009). 
Tabel 2. Karakteristik Petani Berdasarkan Jenis Pekerjaan

\begin{tabular}{llll}
\hline No & \multicolumn{1}{c}{ Uraian } & Jumlah Responden & Persentase (\%) \\
\hline 1 & Pekerjaan Pokok & 30 & 100 \\
& a. Petani & 30 & 100,00 \\
& Jumlah & & \\
$2 \quad$ Pekerjaan Sampingan & 4 & 57,14 \\
& a. Buruh & 2 & 28,57 \\
& b. Tukang & 1 & 14,29 \\
& c. Dagang & 7 & 100 \\
\hline
\end{tabular}

Sumber : Data Primer Diolah (2015)

Tenaga kerja yang digunakan untuk mengelola usahatani padi sawah dengan menggunakan Satuan hari Kerja Setara Pria (HKSP). Pada kegiatan persemaian rata-rata petani menggunakan tenaga kerja dalam keluarga yaitu sebesar 1,35 HKSP/Mt (Tabel 3). kegiatan ini masih bisa dilakukan oleh tenaga kerja dalam keluarga karena tidak membutuhkan tenaga kerja terlalu banyak.

Pada pengolahan lahan tenaga kerja yang paling banyak digunakan adalah tenaga kerja mesin, sepertin traktor, tenaga kerja manusia (laki-laki) hanya memperbaiki saluran irigasi dan pematang sawah. Dimana pada pengolahan lahan curahan tenaga kerja yang dibutuhkan sebesar 2,13 HKSP/Mt untuk dalam keluarga dan 36 HKSP/Mt untuk tenaga kerja luar keluarga (Tabel 3).

Kegiatan penanaman lebih banyak menggunakan tenaga kerja wanita. Rata- rata tenaga kerja yang digunakan sebesar 1,08 HKSP/Mt untuk tenaga kerja dalam keluarga dan 17,84 HKSP/Mt untuk tenaga kerja luar keluarga (Tabel 3).

Dalam kegiatan pemeliharaan disini meliputi kegiatan penyulaman, pemupukan, penyemprotan dan penyiangan. Kegiatan penyulaman biasanya rata-rata curahan tenaga kerja yang dibutuhkan sebesar 1,20 HKSP/Mt(Tabel 3). Pada kegiatan ini tenaga kerja yang digunakan berasal dari dalam keluarga. Sedangkan untuk kegiatan pemupukan sebesar 3,11 HKSP/Mt dan penyemprotan sebesar 1,17 HKSP/Mt (Tabel 3) dalam kegiatan ini menggunakan tenaga kerja laki-laki dan menggunakan tenaga kerja dalam keluarga. Kegiatan penyiangan dengan rata-rata tenaga kerja yang dibutuhkan sebesar 3,67 HKSP/Mt untuk tenaga 
keraja dalam keluarga dan 3,23 HKSP/Mt untuk tenaga kerja luar keluarga (Tabel 3). Pada kegiatan pemanenan semua petani menggunakan tenaga kerja luar keluarga. Tenaga kerja yang dibutuhkan untuk pemanenan sebesar 3,84 HKSP/Mt untuk dalam keluarga dan 34,39 HKSP/Mt untuk luar keluarga (Tabel 3).

Tahap terakhir dari kegiatan adalah pascapanen. Kegiatan ini meliputi penjemuran (pengeringan) dan pengangkutan. Tenaga kerja yang dibayar digunakan dalam fase pengangkutan adalah tenaga kerja laki-laki luar keluarga, sedangkan pada penjemuran petani hanya menggunakan tenaga kerja dalam keluarga baik laki-laki maupun wanita, dimana besarnya tenaga kerja yang digunakan oleh petani sebesar 4,68 HKSP/Mt (Tabel 3).

\section{Penggunaan Faktor Produksi}

Tenaga kerja yang digunakan untuk mengerjakan usahatani padi ini terdiri dari tenaga kerja pria, wanita dan tenaga kerja mesin (Ade et al., 2013). Rata-rata penggunaan tenaga kerja didaerah penelitian adalah sebesar 121,52 HKSP/Mt (Tabel 3).

Menurut Mubyarto (1989) luas lahan yang ditanam akan berpengaruh terhadap peningkatan produksi usahatani. Hasil penelitian menunjukkan rata-rata luas lahan yang dikelola petani sekitar 0,92 Ha dengan kisaran 0,45-2 Ha.

Pupuk yang digunakan dalam penelitian ini dalah pupuk Urea, KCL, TSP. Ratarata penggunaan pupuk urea di daerah penelitian sebesar sebesar 199,90 Kg/Ha , pupuk KCL sebesar 48,78 $\mathrm{Kg} / \mathrm{Ha}$ dan $111,08 \mathrm{Kg} / \mathrm{Ha}$ untuk pupuk TSP. Pupuk Urea lebih banyak dibutuhkan oleh tanaman padi (Tabel 4).

Pestisida Decis yang digunakan sebesar 0,69 Ltr/Mt atau 0,88 ltr/ha, Matador sebesar 0,23 Ltr/Mt atau 0,29 Ltr/Ha dan Lindomin sebesar $0,29 \mathrm{Ltr} / \mathrm{Mt}$ atau 0,38 Ltr/Ha (Tabel 4).

Dari hasil penelitian diketahui bahwa semua petani di daerah penelitian menggunakan benih unggul IR 64. Menurut Merliyanto (2006) bahwa benih unggul hanya bertahan empat musim tanam, karena timbul biotipe baru hama wereng coklat. Rata-rata penggunaan benih di daerah penelitian sebesar 36,77 $\mathrm{Kg} / \mathrm{Mt}$ atau 39,80 Kg/Ha.

Pengembangan Komoditas padi sawah yang berorientas agribisnis, seharusnya di dukung oleh alat dan mesin pertanian, antara lain traktor (Saeful et al., 2009). Petani yang menggunakan traktor sebesar 96,67\% atau 29 dari 30 responden. 
Tabel 3. Rata-Rata Penggunaan Tenaga Kerja Dalam Kegiatan Usahatani Padi Sawah

\begin{tabular}{llcll}
\hline \multirow{2}{*}{ No } & Jenis Pekerjaan & \multicolumn{3}{c}{ Rata-rata Tenaga Kerja HKSP/Mt } \\
\cline { 3 - 5 } & & TKDK & TKLK & \multicolumn{1}{c}{ Total TK } \\
$($ HKSP/Mt $)$ & $($ HKSP/Mt $)$ & 38,13 \\
\hline 1 & Pengolahan lahan & 2,13 & 36 & 1,35 \\
2 & Persemaian & 1,35 & 0 & 22,02 \\
3 & Penanaman & 1,03 & 20,99 & \\
4 & Pemeliharaan & & & 1,20 \\
& $\bullet$ Penyulaman & 1,20 & 0 & 3,11 \\
& $\bullet$ & 3,11 & 0 & 1,17 \\
& $\bullet$ Pemupukan & 1,17 & 0 & 6,9 \\
& • Penyemprotan & 3,67 & 3,23 & 38,23 \\
5 & Pemanenan & 3,84 & 34,39 & 4,73 \\
6 & Pengangkutan & 0 & 4,73 & 4,68 \\
7 & Penjemuran & 4,68 & 0 & 121,52 \\
\hline
\end{tabular}

Sumber : Data Primer Diolah (2015)

Tabel 4. Rata-Rata Penggunaan Pupuk dan Pestisida Oleh Petani

\begin{tabular}{|c|c|c|c|c|}
\hline No & Faktor Pruduksi & Jenis & Rata-Rata $(\mathrm{Kg} / \mathrm{MT})$ & Rata-Rata $(\mathrm{Kg} / \mathrm{Ha})$ \\
\hline \multirow{4}{*}{1} & \multirow{4}{*}{ Pupuk } & Urea & 182,50 & 199,90 \\
\hline & & KCL & 42,00 & 48,78 \\
\hline & & TSP & 98,33 & 111,08 \\
\hline & & Jumlah & 322,83 & 359,76 \\
\hline \multirow{4}{*}{2} & \multirow{4}{*}{ Pestisida } & Decis & 0,69 & 0,88 \\
\hline & & Matador & 0,23 & 0,29 \\
\hline & & Lindomin & 0,29 & 0,38 \\
\hline & & Jumlah & 1,18 & 1,55 \\
\hline
\end{tabular}

Sumber :Data Primer Diolah (2015) 
Tabel 5. Rata-Rata Harga Input dan Output di Tingkat Petani

\begin{tabular}{lll}
\hline No & Uraian & Besarnya (Rp) \\
\hline 1 & Harga Input & \\
& a. Tingkat Upah (/HKSP) & $28.092,59$ \\
& b. Harga Benih $(/ \mathrm{Kg})$ & $2.986,67$ \\
& c. Harga Pupuk $(/ \mathrm{Kg})$ & 5.632 \\
& d. Harga pestisida $(\mathrm{Ltr})$ & $310.888,89$ \\
2 & Harga Output $(\mathrm{Gabah})(/ \mathrm{Kg})$ & $1.811,11$ \\
\hline Sumber $:$ Data Primer Diolah $(2015)$ &
\end{tabular}

\section{Harga Input dan Output}

Upah rata-rata yang dibayar petani karena adanya penggunaan tenaga kerja luar keluarga adalah sebesar $\mathrm{Rp}$ 28.092,59/HKSP (Tabel 5). Harga benih yang diperoleh petani mempunyai ratarata $\mathrm{Rp} 2.986,67 / \mathrm{Kg} / \mathrm{Mt}$ (Tabel 5). Harga standar benih yang ditetapkan diterima pedagang di daerah yaitu $\mathrm{Rp}$ 2.300/Kg/Mt. Harga rata-rata pupuk yang digunakan dalam penelitian ini $\mathrm{Rp}$ 5.632/Kg/Mt (Tabel 5). Harga pupuk yang diterima pedagang dari pemerintah yaitu Rp 4.500/Kg/Mt (Tabel 5). Pestisida yang digunakan dalam penelitian ini adalah harga Decis,Matador dan Lindomin (Tabel 4). Harga rata-rata untuk pestisida adalah Rp 310.888,89 /Ltr/Mt (Tabel 5). Harga rata-rata gabah yang diterima oleh petani adalah sebesar Rp 1.811,11/Kg/Mt (Tabel 5). Harga gabah yang diterima pedagang pengumpul dari pemerintah adalah Rp 2.000/kg/Mt. Sebagian besar petani telah menggunakan benih unggul bersertifikat varietas IR 64 yang diperoleh dari Kios Pertanian.

\section{Uji Asumsi Klasik}

\section{a. Uji Asumsi Klasik Multikolinearitas}

Hasil uji multikolinearitas diketahui bahwa hasil tolerance pada masing-masing variabel lebih besar dari 0,1 sedangkan nilai Varians Inflation Factor (VIF) lebih kecil dari 10 (Tabel 6). Sehingga model regresi dalam penelitian ini tidak ada masalah multikolinearitas.

\section{b.Uji Asumsi Klasik Heteroskedasitisitas}

Hasil pengujian heteroskedastisitas menunjukkan sebaran titik-titik berada di atas 0 pada sumbu $\mathrm{Y}$ dan titik tersebar sepanjang garis linear. Hal ini tidak terjadi heteroskedastisitas, sehingga penelitian ini layak digunakan (Gambar 1)

\section{c.Uji Asumsi Klasik Autokorelasi}

Pengujian dilakukan dengan menggunakan uji-Durbin Watson (DW) 
pada tinakat kepercayaan 95\%, dengan ketentuan jika hasil D-W terletak antara -2 sampai +2 maka tidak ada autokorelasi. Hasil analisi menunjukkan $\mathrm{d}_{\text {hitung }} 1,77$, maka tidak ada autokorelasi korelasi antara variabel-variabel bebas yang diuji (Tabel 7).

\section{Analisis $\quad$ Faktor-Faktor Yang Mempengaruhi Permintaan Tenaga Kerja Luar Keluarga}

Dari tabel 8, maka persamaan regresinya dapat ditulis sebagai berikut:

$$
\begin{aligned}
Y= & 3,863+76,006 X_{1}-0,035 X_{2}+ \\
& 0,024 X_{3}-0,0000246 X_{4}- \\
& 0,004 X_{5}+0,00002022 X_{6}+ \\
& 34,387 D
\end{aligned}
$$

Tabel 6. Hasil Estimasi Uji Multikolinearitas

\begin{tabular}{llc}
\hline Variabel & \multicolumn{2}{c}{ Collinearity Statistik } \\
\cline { 2 - 3 } & Tolerance & VIF \\
\hline $\mathrm{X}_{1}$ & 0,825 & 1,212 \\
$\mathrm{X}_{2}$ & 0,832 & 1,203 \\
$\mathrm{X}_{3}$ & 0,847 & 1,181 \\
$\mathrm{X}_{4}$ & 0,826 & 1,210 \\
$\mathrm{X}_{5}$ & 0,737 & 1,356 \\
$\mathrm{X}_{6}$ & 0,825 & 1,213 \\
$\mathrm{D}$ & 0,808 & 1,238 \\
\hline
\end{tabular}

Normal P-P Plot of Regression Standardized Residual

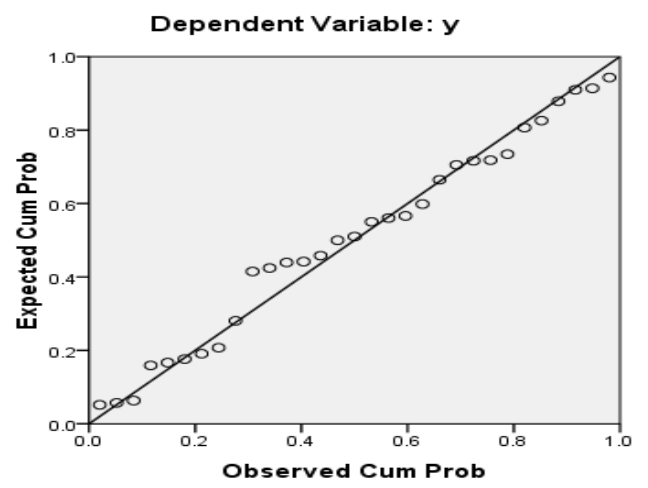

Gambar 1. Hasil Heteroskedastisitas dengan menggunakan grafik 
Tabel 7. Hasil Uji Durbin-Watson pada Tingkat Kepercayaan $95 \%$

\begin{tabular}{ll}
\hline $\mathrm{d}_{\text {hitung }}$ & Kesimpulan \\
\hline 1,77 & Tidak ada autokorelasi \\
\hline
\end{tabular}

Tabel 8. Hasil Estimasi Permintaan Tenaga kerja Luar keluarga Pada Usahatani Padi Sawah

\begin{tabular}{llll}
\hline Variabel Bebas & Koefisien Regresi & Standar Error & T hitung \\
\hline Intersep & 3,863 & 274,759 & 0,014 \\
Luas lahan $\left(\mathrm{X}_{1}\right)$ & 76,006 & 7,019 & $10,828^{*}$ \\
Harga produk $\left(\right.$ gabah) $\left(\mathrm{X}_{2}\right)$ & $-0,035$ & 0,079 & $-0,441^{\mathrm{Ns}}$ \\
Harga pupuk $\left(\mathrm{X}_{3}\right)$ & 0,024 & 0,026 & $0,924^{\mathrm{Ns}}$ \\
Harga pestisida $\left(\mathrm{X}_{4}\right)$ & $-2,462 \mathrm{E}-6$ & 0.000 & $-0,082^{\mathrm{Ns}}$ \\
Harga benih $\left(\mathrm{X}_{5}\right)$ & $-0,004$ & 0.046 & $-0,095^{\mathrm{Ns}}$ \\
Upah tenaga kerja $\left(\mathrm{X}_{6}\right)$ & $2,022 \mathrm{E}-5$ & 0,001 & $2,082^{*}$ \\
Dummy $=$ Cara Pengolahan lahan $(\mathrm{D} 1)$ & 34,387 & 16,162 & $-2,128^{*}$ \\
\hline R $=0,927$ & & & \\
T tabel $= \pm 2,074(\alpha=0,05 / 2)$ & & & \\
F tabel $=\quad 2,46(\alpha=0,05)$ & & & \\
F hitung $=19,317$ & & \\
\hline Keterangan $: *=$ Nyata pada taraf kepercayaan $95 \%$, Ns= Berpengaruh tidak nyata pada taraf kepercayaan $95 \%$
\end{tabular}

\section{a.Luas lahan}

Luas lahan berpengaruh nyata terhadap permintaan tenaga kerja luar keluarga, hal ini ditunjukkan dengan $\mathrm{t}$ hitung $(10,828)>\mathrm{t}$ tabel (2,074). Nilai koefisien regresi luas lahan sebesar 76,006. Hasil penelitian ini sejalan penelitian Lismidi (2004) yang menyatakan bahawa luas lahan merupakan faktor produksi yang utama dalam usahatani padi, dalam penggunaan luas lahan berpengaruhi positif terhadap permintaan tenaga kerja sewa.

\section{b.Harga Gabah}

Harga gabah berpengaruh tidak nyata terhadap permintaan tenaga kerja luar keluarga, hal ini ditunjukkan hasil uji $\mathrm{t}$ dengan $\mathrm{t}$ hitung $(-0,441)>\mathrm{t}$ tabel $(2,074)$. Nilai koefisien regresi harga gabah sebesar -0,035 menunjukkan bahwa apabila terjadi kenaikan setiap satu satuan harga gabah maka akan ada kecenderungan untuk menurunkan permintaan tenaga kerja luar keluarga. 


\section{c.Harga Pupuk}

Harga pupuk tidak berpengaruh nyata terhadap permintaan tenaga kerja luar keluarga, hal ini ditunjukkan hasil uji $\mathrm{t}$ dengan $t_{\text {hitung }}(0,924)<t$ tabel $(2,074)$. Nilai koefisien regresi harga pupuk sebesar 0,024 menunjukkan bahwa apabila terjadi kenaikan setiap satu satuan harga pupuk

\section{e.Harga Pestisida}

Harga pestisida berpengaruh tidak nyata terhadap permintaan tenaga kerja luar keluarga hal ini ditunjukkan hasil uji $\mathrm{t}$ dengan $\mathrm{t}$ hitung $(-0,082)>\mathrm{t}$ tabel $(2,074)$. Nilai koefisien regresi harga pestisida sebesar -0,000002462 menunjukkan bahwa apabila terjadi kenaikan setiap satu satuan harga pestisida maka akan ada kecenderungan untuk menurunkan permintaan tenaga kerja luar keluarga. Hal ini sejalan dengan penelitian Haryanto (1997), yang menyatakan bahwa harga pestisida berpengaruh nyata pada taraf 95\% sehingga dengan kenaikan harga pestisida dapat menurunkan permintaan tenaga kerja sewa.

\section{f. Harga Benih}

Harga benih berpengaruh tidak nyata terhadap permintaan tenaga kerja luar keluarga hal ini ditunjukkan hasil uji $\mathrm{t}$ dengan $\mathrm{t}$ hitung $(-0,095)>\mathrm{t}$ tabel $(2,074)$. Nilai koefisien regresi harga benih sebesar $-0,004$. menunjukkan bahwa apabila terjadi kenaikan setiap satu satuan harga pupuk maka akan ada kecenderungan untuk menurunkan permintaan tenaga kerja luar. Hal ini tidak sejalan dengan penelitian Merliyanto (2006) yang menyatakan bahwa harga benih tidak berpengaruh nyata terhadap permintaan tenaga kerja pada taraf kepercayaan $95 \%$.

\section{g.Upah Tenaga kerja}

Upah tenaga kerja berpengaruh nyata terhadap permintaan tenaga kerja luar keluarga hal ini ditunjukkan hasil uji $\mathrm{t}$ dengan $\mathrm{t}$ hitung $(2,082)>\mathrm{t}$ tabel $(2,074)$. Nilai koefisien regresi upah tenaga kerja sebesar 0,00002022 menunjukkan bahwa apabila terjadi kenaikan setiap satu satuan tingkat upah maka akan ada kecenderungan untuk meningkatkan permintaan tenaga kerja luar keluarga.

\section{h.Dummy variabel}

Dummy variabel yaitu cara pengolahan lahan berpengaruh secara nyata terhadap permintaan tenaga kerja. Hal ini ditunjukkan dari hasil uji $\mathrm{t}$ hitung $(-2,128)$ $>\mathrm{t}$ tabel (2,074). Nilai koefisien regresi sebesar 34,837 artinya pengolahan lahan dengan menggunakan traktor akan meningkatkan permintaan tenaga kerja luar keluarga. 


\section{KESIMPULAN}

Permintaan tenaga kerja pada usahatani padi sawah adalah 22,18 HKSP/Mt untuk tenaga kerja dalam keluarga dan 99,34 HKSP/Mt untuk tenaga kerja luar keluarga.

Peningkatan luas lahan, upah tenaga kerja, dan pengolahan menggunakan traktor akan meningkatkan permintaan tenaga kerja luar keluarga. Peningkatan setiap satu satuan harga gabah, harga pupuk, harga pestisida, dan harga benih akan menurunkan permintaan tenaga kerja luar keluarga.

\section{DAFTAR PUSTAKA}

Ade, C, P., Made, S., Putu, U, W. 2013. Analisis faktor-faktor yang mempengaruhi produksi padi sawah Kota Denpasar. Jurnal Agribisnis dan Agrowisata 2(3) : 89-98

Anonim. 2014. Profil Desa Ujung Tanjung III. Kabupaten Lebong.

Antoni. 2004. Analisis Permintaan

Tenaga Kerja Pada Usahatani Padi

(Studi kasus di Desa Kepala Curup Kecamatan Padang Ulak Tanding,

Kab. R/L). Skripsi Fakultas

Pertanian.UNIB. Skripsi. (tidak dipublikasikan).

Atman. 2007. Teknologi budidaya padi sawah varietas unggul di Jawa

Barat. Jurnal Ilmiah Tambua 6 (1) : 58-64

Boediono.1998. Ekonomi Mikro. BPFE.Yogyakarta.

Haryanto. 1997. Analisis Faktor-Faktor yang Mempengaruhi Curahan Hari Kerja pada Usahatani Padi Sawah.
Fakultas Pertanian. UNIB. Skripsi. (tidak dipublikasikan).

Hernanto, F. 1989. Ilmu Usaha Tani. Penebar Swadaya. Jakarta.

Jajat, S., Tri, R, S. 2010. Pembinaan kelompok tani melalui pembuatan dan penggunaan kompos jerami pada tanaman padi sawah Kabupaten Indramayu. Jurnal Penyuluhan Pertanian 5(1) : 78-86

Lismidi. 2004. Analisis Faktor - Faktor yang Mempengaruhi Permintaan Tenaga Kerja Sewa pada Usahatani Padi Sawah di Kecamatan Pino Kabupaten Lebong. Skripsi Fakultas Pertanian.UNIB.Skripsi (tidak dipublikasikan).

Merliyanto, A. 2006. Permintaan Tenaga Kerja Luar Keluarga Pada Usahatani Padi Sawah Dengan Irigasi Teknis dan Non Teknis di Kecamatan Kota Argamakmur Kabupaten Bengkulu Utara. Skripsi Fakultas Pertanian.UNIB.Skripsi (tidak dipublikasikan).

Mubyarto. 1989. Pengantar Ekonomi Pertanian. LP3ES. Jakarta.

Nazir. 2003. Metode Penelitian. Ghalia Indonesia. Jakarta

Saeful, B., Agus, R., Trisna, S. 2009. Penggunaan traktor roda dua pada lahan padi sawah di Jawa Barat. Jurnal Agcicultura 20(3) : 191-197

Seomaoen. 1992. Ekonomi Produksi Pertanian Teori dan Aplikasi. I.S.E.I. Jakart

Simanjuntak. 1998. Pengantar Ekonomi Sumberdaya Manusia Edisi Kedua. Fakultas Ekonomi. UI. Jakarta.

Singarimbun, M dan Effendi, 1989. Metode Penelitian Survey. LP3ES. Jakarta. Persada. Jakarta.

Soekartawi. 1995. Teori Ekonomi Produksi. Raja Grafindo. Jakarta. 